\section{Obscure GI bleeding in a young man}

\section{CLINICAL PRESENTATION}

A 27-year-old healthy man presented with a 3-week history of melena along with iron-deficiency anaemia (haemoglobin: $60 \mathrm{~g} / \mathrm{L}$ ). Upper endoscopy and colonoscopy were performed and were normal. The patient was referred for enteroscopy after capsule endoscopy revealed the presence of blood in the proximal jejunum without visualisation of an underlying lesion.

On further questioning, patient denies having any GI or extraintestinal symptoms prior to onset of melena. He denied having weight changes and had no recent history of non-steroidal antiinflammatory drugs use.

Push enteroscopy was performed using a PENTAX paediatric colonoscope. At $90 \mathrm{~cm}$ beyond the pylorus, note was made of a

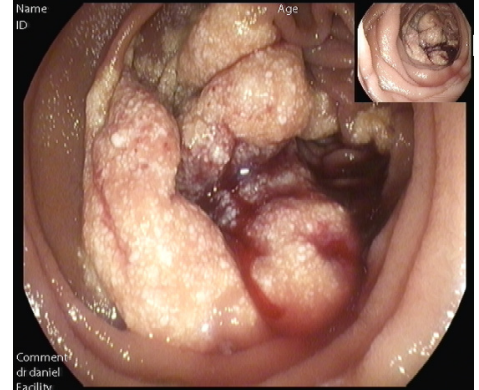

Figure 1 Semicircumferential lobulated mass in the proximal jejunum harbouring multiple whitish nodularities with blood oozing.

semicircumferential mass occupying three to four jejunal folds, harbouring multiple whitish nodularities (figure 1). Mild blood oozing was present.

QUESTION

What is your presumed diagnosis?

See page 2142 for answer 


\section{Obscure GI bleeding in a young man}

See page 2070 for question

\section{ANSWER}

Histopathological examination of biopsy specimens obtained from the mass revealed dilated mucosal lacteals suggestive of a lymphangiomatous lesion. The patient underwent a subsequent laparoscopic segmental jejunal resection. Gross examination findings are described in figure 2A,B.

Findings on histopathology were diagnostic of jejunal lymphangiectasia (figure 3A,B).

Intestinal lymphangiectasia is virtually always an incidental finding without clinical consequences, identified in the duodenum in $1.9 \%$ of adults undergoing routine upper endoscopy and is commonly identified on capsule endoscopy. ${ }^{1}$ Typical features include scattered white plaques and submucosal elevations. ${ }^{2}$ On the rare occasions when the disease is symptomatic, findings tend to be much more extensive, and patients commonly present with symptoms of protein-losing enteropathy. ${ }^{3}$ In that case, the disease can be idiopathic (primary lymphangiectasia), however, ensuring that it is not secondary to other causes is of extreme importance (downstream intestinal obstruction, circulatory problems, infectious and inflammatory processes, or malignant lymphoma). ${ }^{4}$

A less common presentation is occult GI bleeding likely as a result of intestinal ulcerations. ${ }^{4}$ It is quite uncommon for the disease to result in overt GI bleeding such as in our patient. Our case is unique as it offers an atypical location and presentation of a primary localised intestinal lymphangiectasia.

\section{Fady Daniel, ${ }^{1}$ Roni Aoun $\odot$, ${ }^{1}$ Rayan Rammal ${ }^{2}$}

${ }^{1}$ Internal Medicine, Division of Gastroenterology and Hepatology, American University of Beirut, Beirut, Lebanon

${ }^{2}$ Pathology and Laboratory Medicine, American University of Beirut, Beirut, Lebanon

Correspondence to Dr Roni Aoun, Internal Medicine, division of Gastroenterology and Hepatology, American University of Beirut, Beirut 1107 2020, Lebanon; ronigaoun@gmail.com

Contributors FD, RA and RR identified and managed the case. FD planned and supervised the workflow. FD was also the guarantor of the study. RA performed the literature review, wrote the manuscript and adjusted images quality to meet the journal requirements. RR provided pictures of surgical pathology specimen as well as histopathology slides (along with their descriptions).

Funding The authors have not declared a specific grant for this research from any funding agency in the public, commercial or not-for-profit sectors.

Competing interests None declared.

Patient consent for publication Obtained.

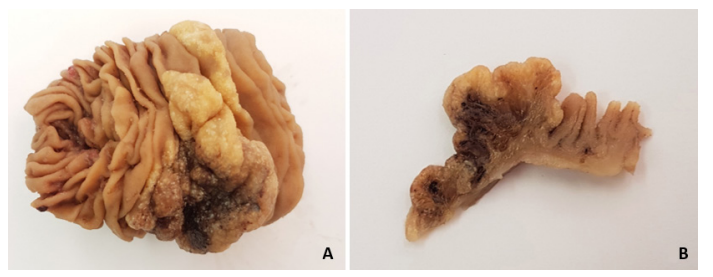

Figure 2 (A) Surgical specimen. Note the edematous aspect of the jejunal mucosa with whitish swollen villi as well as haemorrhagic villi. (B) Full-thickness section showing cystically dilated spaces in the mucosa and submucosa on the left compared with the normal appearance of the jejunal wall on the right.

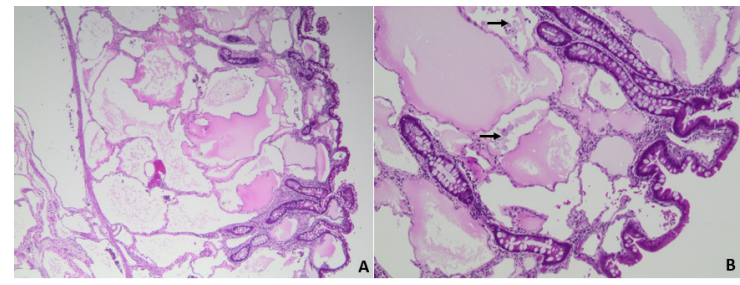

Figure 3 (A) Low power view of dilated lymphatics involving intestinal mucosa and submucosa (H\&E; 40x). (B) High power view showing intestinal mucosal involvement with dilated lymphatics. The latter contain foamy macrophages (arrows) and lymphatic protein. Surface epithelial cells are normal (H\&E; 400x).

Provenance and peer review Not commissioned; externally peer reviewed. (c) Author(s) (or their employer(s)) 2020. No commercial re-use. See rights and permissions. Published by BMJ.

\section{(D) Check for updates}

To cite Daniel F, Aoun R, Rammal R. Gut 2020;69:2142.

Received 16 September 2019

Revised 30 October 2019

Accepted 31 October 2019

Published Online First 19 November 2019

Gut 2020;69:2142. doi:10.1136/gutjnl-2019-319870

ORCID iD

Roni Aoun http://orcid.org/0000-0001-8765-5680

\section{REFERENCES}

$1 \mathrm{Kim} \mathrm{JH}$, Bak YT, Kim JS, et al. Clinical significance of duodenal lymphangiectasia incidentally found during routine upper gastrointestinal endoscopy. Endoscopy 2009;41:510-5.

2 Lom J, Dhere T, Obideen K, et al. Intestinal lymphangiectasia causing massive gastrointestinal bleed. J Clin Gastroenterol 2010;44:74-5.

3 Herfarth $\mathrm{H}$, Hofstädter F, Feuerbach S, et al. A case of recurrent gastrointestinal bleeding and protein-losing gastroenteropathy. Nat Clin Pract Gastroenterol Hepatol 2007;4:288-93.

4 Freeman HJ, Nimmo M. Intestinal lymphangiectasia in adults. World J Gastrointest Oncol 2011:3:19-23. 